\title{
Culture Change in a Professional Sports Team: Shaping Environmental Contexts and Regulating Power
}

\author{
A Commentary \\ Sarah Gilmore \\ Portsmouth Business School \\ University of Portsmouth \\ Richmond Building, Portland Street \\ Portsmouth, PO1 3DE, UK \\ E-mail: Sarah.Gilmore@port.ac.uk
}

\section{INTRODUCTION}

My commentary is situated within my own field of expertise which lies within management and organization studies. This location leads me to be somewhat critical of Cruickshank et al.'s article because the authors took the decision to elide these literatures which I argue are foundational to a really nuanced, developed understanding of the phenomena explored in this study. My comments are restricted to three key areas: i) the issue of professional sports organizations being businesses and the implications of this for culture; ii) the exclusion of theory from management and organization studies literatures; and iii) a critique of methods.

\section{PROFESSIONAL SPORTS TEAMS ARE LOCATED WITHIN BUSINESS ORGANIZATIONS}

My first critique lies in the location of the study and the refusal to view the club holistically; preferring to narrow down the focus of the study to the team. Smith and Stewart [1] have argued that sport's economic and social progress has created diverse and heterogeneous systems that are hard to categorise. Given this heterogeneity of systems and structures and the implications these have for organizational and team cultures, I would argue that a more holistic frame of reference is needed in order to attempt to make sense of aspects of the more visible and accessible features of culture. Even from a perspective that focuses more on institutional isomorphism and homogeneity, this wider perspective is valuable because the team is part of a wider context which not only consists of the 'business' entity that exists alongside it and consistently interacts with it, but the organization as a club entity is caught up in and shaped by institutional logics operating both at the level of the institutional field and at the intraorganizational level; exerting powerful influences on the range and scope of activities and behaviour at all levels of the organization, thus shaping the cultures of institutions and institutional practices [2].

At the intraorganizational level, owners and CEOs often directly intervene in performance departments. They sack managers, they can determine targets for a season or across seasons; developing strategies as to where the club/team should be in terms of league performance over a period of time. They also determine the resources a manager has at his/her disposal 
for any given season. Issues of resourcing have profound implications for culture, especially when pertaining to changing organizational/team structures. As noted by Anthony [3], many cultural change initiatives are intertwined with changes in organizational structure, to the extent that it is difficult to isolate 'culture' as a variable when attempting to measure its effects when assessing a cultural change initiative. A manager's ability to engage in making alterations here - bringing in new staff and potentially jettisoning existing ones - often has to be signed off by the CEO and/or the Board of Directors with the success of this activity being highly dependent upon managerial rhetoric; ensuring a fit here with the strategic direction of the club as a (business) entity, and being subject to evaluation by the entity that consents to its enactment.

\section{THE FALLACY OF EXCLUDING MANAGEMENT AND ORGANIZATION STUDIES}

My main theoretical objection to Cruickshank et al.'s article is the rejection of work on organizational culture from the management and organization studies (MOS) domain. Given the focus on organizational culture witnessed here - from the 1950s onwards - this seems inexplicable. One of the contributions made by writers from this perspective which could have had a foundational impact on this study concerns how we define it. Linstead and Grafton-Small [4, p. 333] argue that a distinction can be made between corporate culture and organizational culture. The former is devised by management and transmitted or marketed on the rest of the organization, with both internal and external images yet also including action and belief - the rites and rituals, stories and values which are offered to organizational members as part of the seductive process of achieving membership and gaining commitment. The latter, however, is that which grows or emerges within the organization and which emphasises the creativity of organizational members as culture-makers, perhaps resisting the dominant culture. This kind of activity is missing from the article and culture seems to be viewed as being essentially owned by managers and almost viewed as an object rather than as an evolving entity. Smircich [5]) argues that cultural processes do not operate in a unified way - as is presented in the article - and instead posits a view that culture is something that an organization 'is' rather than 'has'. Taken further, we can see culture as being fragmentary, incomplete, contradictory, disrupted and it neither stops nor starts when we want it to. It is not a phenomenon that can be completely controlled - although, as this case illustrates, it can be manipulated. It is this lack of focus on agency that concerns me about this article, because it seems to be operating as a mode of concertive control [6]. Through his ethnographic study of a small engineering firm, Barker [6] shows how the operation of self-managed teams developed a system of value-based, normative rules that controlled their actions more completely than their former system and made resistance to it almost impossible.

Yet autobiographies and biographies of professional sportsmen and women are replete with stories of resistance and rebellion to the regimes that they are subjected to. These can be cultural, managerial or pertain to a rebellion against dietary or other sports science restrictions. They can also highlight the existence of subcultures that might exist below the radar of the management team and will not be exposed via research instruments such as questionnaires or even focus groups. For example, the existence of a culture unique to the goal-keeping staff at one Premier League club I worked within only became apparent to me via a relaxed conversation with an 'honorary member' of the goal keeping fraternity after having worked with the team for some period of time. The cultural rituals adopted by this small group of players would certainly have broken many of the regulations set down by sports science staff - yet they were also facilitated by at least two of them; highlighting the 
tensions and contradictions operating via cultural practices and rituals. This leads to my third area of critique.

\section{METHODOLOGY}

The work of Schein [7] sees culture as being composed of three levels consisting of artefacts and creations, underpinned by values and basic assumptions - the latter two levels being increasingly opaque and hard to access. He also argues that the culture reveals itself when it is most stressed, when presented with problems and challenges, rather than in its routine thus having similarities with Charles Hampden-Turner's dilemma-centred view of culture. This has an important methodological consequence: to observe what a culture does when faced by problems, you have to be there, you cannot rely upon questionnaires or even semistructured interviews. Further, if culture is unconscious, or if it operates somewhat secretively, then it cannot be easily articulated or easily accessed. Questionnaires, focus groups and semi-structured interviews can therefore only access the known, visible, and pretty unremarkable aspects of culture. However, as noted by Linstead [8], many studies of culture rely on such instruments leading many social anthropologists to argue that what is elicited here is not culture but the outline of changes made by new managers to improve performance. These will have had an impact on the team's cultures, but I would argue that these are not really uncovered here and are tantalisingly absent.

\section{CONCLUSION}

I found this an interesting - albeit frustrating - article to read. The data presented is appealing - as such studies often are because of the characters and the stories they tell. However, I would query the extent to which this article really gets to grips and uncovers issues pertaining to culture. Alternatively, I would argue that this article is actually concerned much more with a managerially-led and imposed programme of change management. Now this will have had an impact on organizational, team and other cultures, but the extent to which these were identified and explored is moot.

\section{REFERENCES}

1. Smith, A.C.T. and Stewart, B., The Special Features of Sport: A Critical Revisit, Sport Management Review, 2010, 13(1), 1-13.

2. Scott, W.R., Institutions and Organizations: Ideas and Interests, Sage, London, 2007.

3. Anthony, P., Managing Culture, Open University, Buckingham, 1994.

4. Linstead, S. and Grafton Small, R., On Reading Organizational Culture, Organization Studies, 1992, 13(3), $331-55$.

5. Smircich, L., Concepts of Culture and Organizational Analysis, Administrative Science Quarterly, 1983, 28(3), 339-58.

6. Barker, J., Tightening the Iron Cage: Concertive Control in Self-Managing Teams, Administrative Science Quarterly, 1993, 38(3), 408-437.

7. Schein, E. (1985). Organizational Culture and Leadership, Jossey-Bass, San Francisco, CA, 1985.

8. Linstead, S., Managing Culture, in: Linstead, S., Fulop, L. and Lilley, S., eds., Management and Organization: A Critical Text, Palgrave, Basingstoke, 2009. 
